\title{
1 \\ NUMERICAL ESTIMATION OF STRESS INTENSITY FACTORS IN PATCHED CRACKED PLATES
}

\author{
RAMESH CHANDRA and K. GURUPRASAD
}

Structures Division, National Aeronautical Laboratory, Bangalore, India

\begin{abstract}
The fatigue and fracture performance of a cracked plate can be substantially improved, by providing patches as reinforcements. The effectiveness of the patches is related to the reduction they cause in the stress intensity factor (SIF) of the crack. So, for reliable design, one needs an accurate evaluation of the SIF in terms of crack, patch and adhesive parameters. In this investigation a finite element technique to compute the SIF through the $J$-integral for patched cracked plates is presented. TRIM6 and TRUMPL elements of ASKA are employed to model cracked sheet and cracked sheet-adhesives-patch regions, respectively. Path independency of $J$-integral for unpatched plates is shown by considering many contours. For patched plates, the contours chosen do not enclose the patch-cracked sheet region. The values of SIF's are obtained for unpatched edgecracked, unpatched centre-cracked and patched centre-cracked plates. These values are compared with the analytical and numerical results existing in the literature. This study shows that conventional finite elements can be used to model patched cracks and reasonable estimate of SIF can be made via the $J$-integral.
\end{abstract}

\section{NOTATION}

\author{
$J$-integral \\ Contour surrounding the crack tip \\ Traction vector defined according to the outward normal along $\Gamma$, Fig. 1 \\ Displacement vector at a point on contour, $\mathbf{u}=i u+j v$ \\ Arc length along the contour \\ Crack length and semi crack length for edge crack and centre-crack plates respectively \\ Width and semi width for edge-crack and centre-crack plates respectively \\ Length of plates \\ State of stress at a point $(x, y)$ \\ State of strain at a point $(x, y)$ \\ Young's modulus of the cracked plate \\ Strain energy density, $1 / 2\left(\sigma_{x} \varepsilon_{x}+\sigma_{y} \varepsilon_{y}+\sigma_{x y} \varepsilon_{x y}\right)$ \\ Directions perpendicular and parallel to crack line \\ Stress Intensity Factor (SIF) \\ Reference value of SIF \\ SIF for patched plate \\ SIF for unpatched plate \\ Applied stress \\ Thickness of patch \\ Thickness of sheet
}

\section{INTRODUCTION}

THE 'FAIL SAFE' concept is widely used in the design of aircraft structural components. The design of such 'damage tolerant' structures is governed by detailed specifications [1,2], which are intended to ensure that a specified fatigue crack will not grow to critical proportions in a period between successive routine inspections.

Fatigue cracked components are often repaired in service. Standard repair schemes normally involve strengthening the component by connecting a reinforcing member by means of bolts or rivets and thereby reducing the crack tip stress intensity factors.

Recent technological advances in fibre reinforced composite materials and adhesive bonding have led to the development of efficient repair schemes using these. In such repairs, (a) the load transfer between component and reinforcement is affected with minimal stress concentration efects, (b) the properties and geometry of the reinforcement can be tailored to suit the particular application and (c) composite repair patch does not add significantly to the weight of the component. Boron-epoxy, boron-aluminium and carbon-epoxy have been used in some repair schemes for aircraft structures $[3,4]$. A general research programme on development of methodology for design 
of reinforcement in cracked plates is currently being pursued at National Aeronautical Laboratory, India[5-8]. An efficient design of the reinforcement (patch) needs estimation of the resulting stress intensity
factor (SIF) at the crack tip in the patched panel.

There have been numerous attempts[9-12] to compute SIF of patched cracked plates. These are based on the finite element technique using special elements with displacement[13] or hybrid formulation[14].

In this investigation a finite element technique to compute SiF through the $J$-integral for patched cracked plates is presented. TRIM6 and TRUMPL elements of ASKA are employed to model cracked sheet and cracked sheet-adhesives-patch regions respectively. Path independency of the $J$-integral for unpatched plates is shown by considering many contours. For patched plates, the contours chosen do not enclose the patch-cracked sheet region. The values of SIF's are obtained for unpatched edge-cracked, unpatched centre-cracked and patched centre-cracked-plates. These values are compared with the analytical and numerical results existing in the literature. This study shows that conventional finite elements can be used to model patched cracks and reasonable estimate of SIF can be made via the $J$-integral.

\section{COMPUTATION OF STRESS INTENSITY FACTOR VIA J-INTEGRAL}

Rice[15] proved the existence of path-independent contour integral for two dimensional deformation field in the absence of body forces. This integral is given as:

$$
J=\int_{\Gamma} w \mathrm{~d} y-\mathbf{T} \cdot \frac{\partial \mathbf{u}}{\partial x} \mathrm{~d} s .
$$

For a general contour,

$$
\mathbf{T} \cdot \frac{\partial u}{\partial x}=\frac{\partial u}{\partial x}\left(\sigma_{x} \frac{\mathrm{d} y}{\mathrm{~d} s}-\sigma_{x y} \frac{\mathrm{d} x}{\mathrm{~d} s}\right)+\frac{\partial v}{\partial x}\left(\sigma_{x y} \frac{\mathrm{d} y}{\mathrm{~d} s}-\sigma_{y} \frac{\mathrm{d} x}{\mathrm{~d} s}\right) .
$$

He considered a closed contour $\left(A_{1} B_{1} C_{1} A B C D E F A_{1}\right.$ in Fig. 1a) around crack tip, applied Green's theorem to convert line integral into an area integral and showed that this contour integral was zero. He further used the conditions on the crack faces $\left(F A_{1}\right.$ and $\left.A C_{1}\right)$ and proved the path independency of the contour integral. The limitation of the existence of this integral therefore are:

(1) No body forces

(2) Crack faces not loaded

(3) No discontinuity in the region between $\Gamma_{1}$ and $\Gamma_{2}$.

Figure 1 shows the contours required to be considered for cracked plates with and without patches. It is to be noted that the valid paths for different configurations are different from each other.

Although the $J$-integral was originally intended to be applicable in Linear Elastic Fracture Mechanics (LEFM) regime, it has been extended to Elastic Plastic Fracture Mechanics (EPFM) regime by many investigators. Some of the important contributions are briefly reviewed here.

Kobayashi[16] used a finite element technique and an experimental technique based on compliance (load-deflection) to evaluate $J$-integral values for a highly ductile material. He showed the path independency of the $J$-integral for this material up to fairly high loads and the pre and post crack extension situations. Read et al.[17, 18] in their search for valid fracture criteria for their 'fitness for service assessment methodology' program examined the $J$-integral and the COD and concluded that the $J$-integral would be the most appropriate criterion for EPFM. Finite element method using nonlinear crack tip element, experimental methods using load vs elongation and contour integrating of the 'integrand' established by strain gauge measurements were each employed to evaluate the $J$-integral for a number of configurations. A good correlation between the three techniques was achieved in one case and it was felt that similar agreement was not achieved in other cases due to difficulties in the experimental techniques. King and Herrmann[19] 
presented an experimental evaluation of the $J$-integral in LEFM and EPFM regimes using ultrasonic velocity measurements.

Frediani[20] presented experimental and theoretical evaluation of the $J$-integral for aluminium alloys (2024 and 7075). Theoretical study was hased on finite element technique employing 3 noded singular isoparameteric element. The path independence was shown by considering 14 different paths and accepting the 22 per cent variation in the $J$-values. Experimental evaluation was based on direct contour integration of the 'integrand' estimated with the help of strain gauges. The

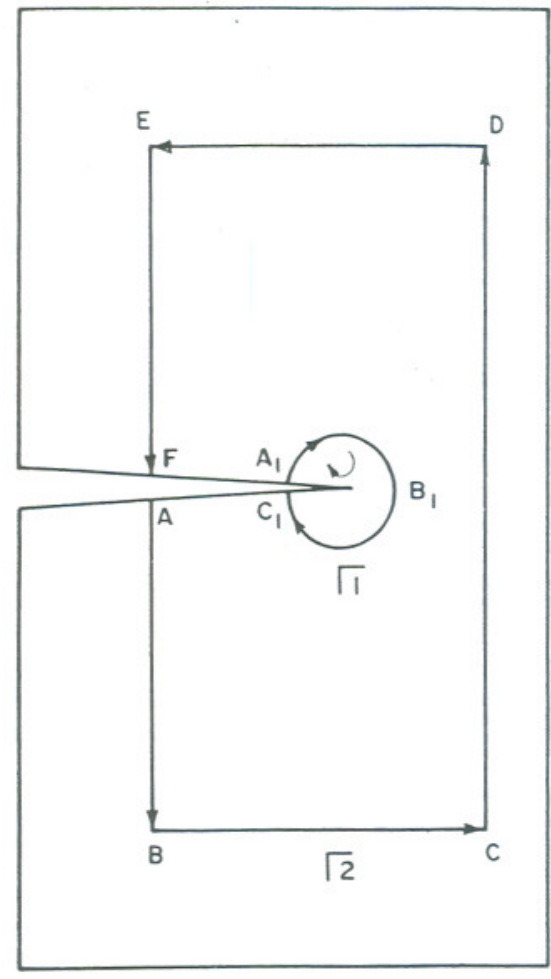

a

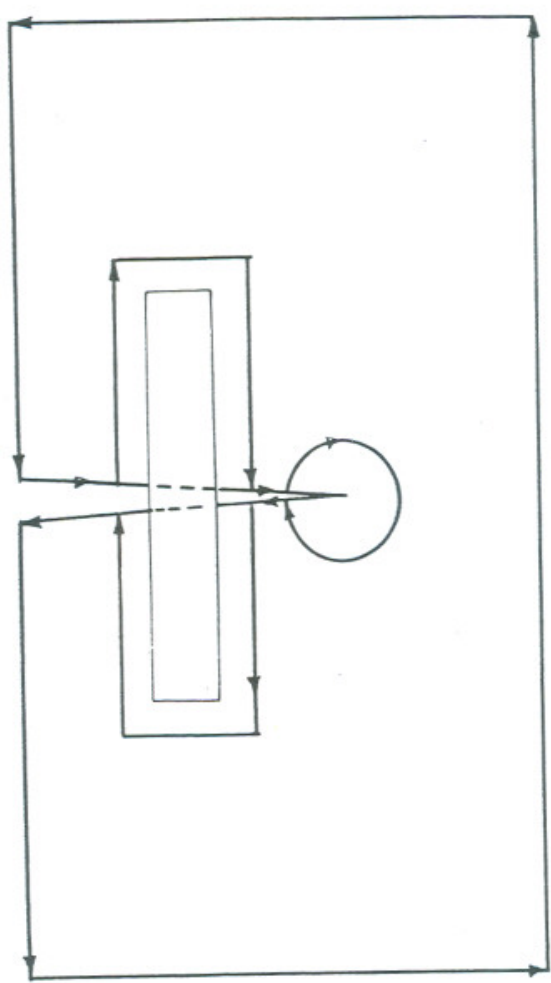

C

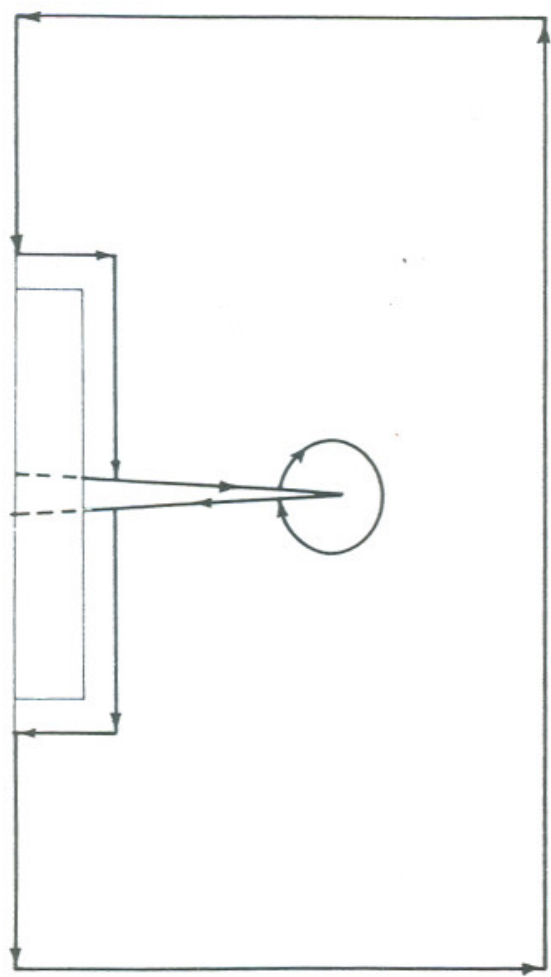

b

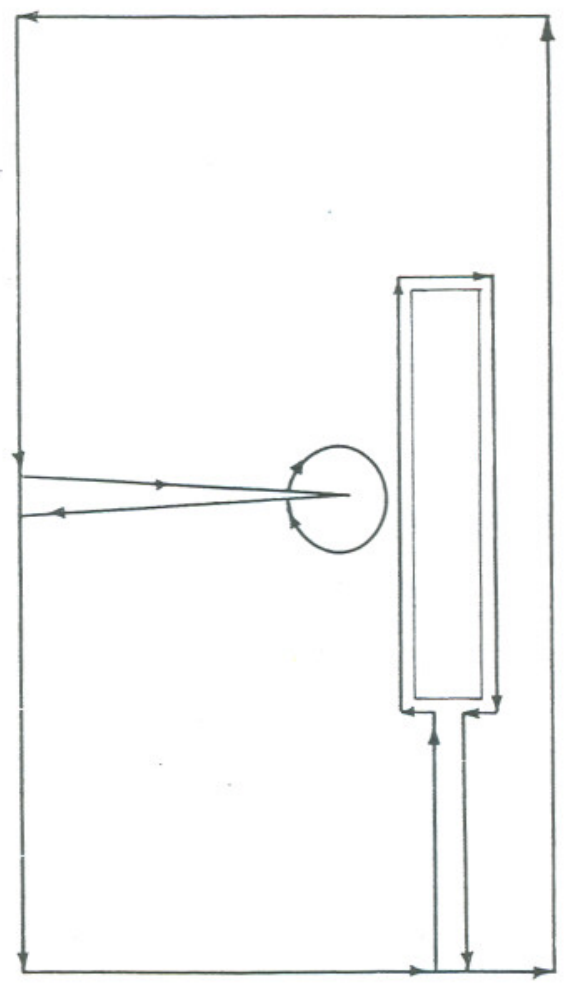

d

Fig. 1. (a) Contour for cracked plate without patch. (b, c, d) Contours for cracked plate with patch at various positions. 
loaded edges of centre-cracked specimens were reinforced with stiff plates to ensure uniform displacement at the edges. However to ensure whether or not it is realised, specimen with no crack length was tested. This test, by resulting a nonzero value of $J$, revealed that uniform displacement condition was not achieved. This nonzero value of $J$ at various load levels was considered to be the error due to non uniformity of displacement at the edges. Under the assumption that this error is independent of crack length, the values of the $J$-integral were evaluated by incorporating this error. Although this method avoids the measurements of the displacements at the loading edges, it is highly unsatisfactory as, in principle, the correction factor definitely depends upon crack length.

Thus it appears that the $J$-integral has been computed theoretically and experimentally in LEFM and EPFM situations for cracked bodies without reinforcement. For the present problem of patched crack plates, experimental evaluation of contour integral by direct measurement of integral becomes very complex as the stress and displacement fields are to be measured along the contour in the interior of the body. Hence we numerically estimate $J$ integral for this problem in LEFM regime only. In LEFM, SIF and $J$-integral are connected by

$$
K=(J E)^{1 / 2}
$$

SIF's are computed by employing equation (2).

\section{FINITE ELEMENT MODELLING}

TRIM6 and TRUMPL of ASKA were used to model the cracked sheet and the cracked sheet-adhesive-patch regions respectively. TRIM6 is a six noded triangular membrane element with three translational degrees of freedom per node. TRUMPL is a three noded triangular layered
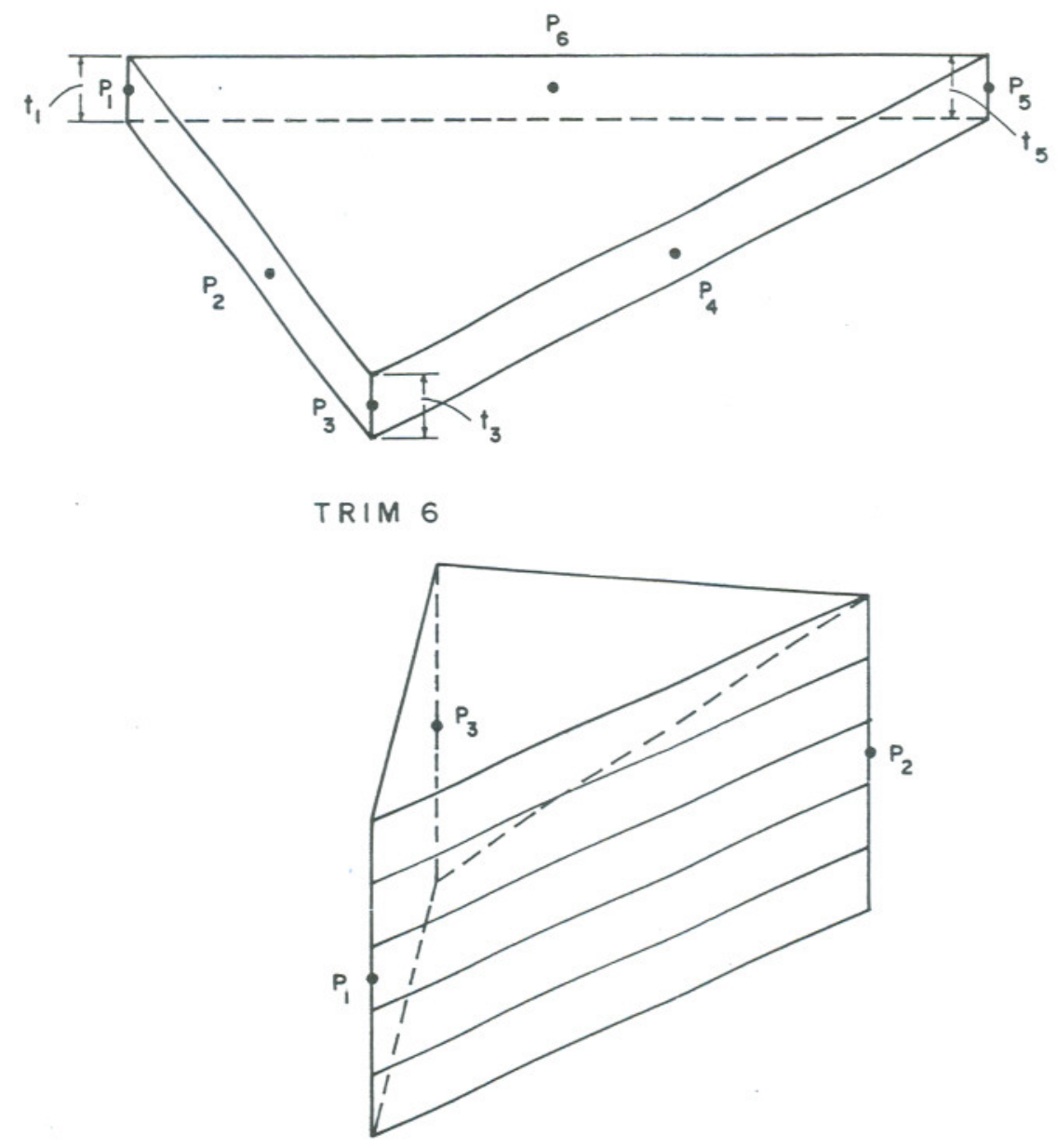

TRUMPL

Fig. 2. TRIM6 and TRUMPL elements of ASKA. 
Table 1. Convergence study-edge-cracked plate without patch

\begin{tabular}{rcc}
\hline No. of nodes & $K / \sigma \sqrt{\pi a}$ & Error (per cent) \\
\hline 531 (mesh 1) & 2.7644 & 7.80 \\
682 (mesh 2) & 2.8876 & 3.75 \\
1119 (mesh 3) & 2.9012 & 3.29 \\
1119 (mesh 4) & 3.0208 & 0.70 \\
\hline
\end{tabular}

$h / b=0.5 ; a / b=0.5$.

$K_{\mathrm{ref}} / \sigma \sqrt{\pi a}=3.00[21]$

plate element with six degrees of freedom ( 3 translations and 3 rotations) per node. The layers can have anisotropic properties. Figure 2 shows these elements.

\section{ILLUSTRATIONS}

\section{Edge-cracked plates without patches}

An edge-cracked plate without patches subjected to uniform tensile load was considered as the first test example. In order to establish convergence, four meshes were generated using FEMGEN of ASKA and values of SIF via the $J$-integral were computed by employing ten point Gaussian quadrature integration. Loading edge was considered to be unconstrained. Table 1 shows the values of SIF corresponding to these meshes. Figure 3 shows the mesh 4 which corresponds to the converged solution. For computation of contour integral ( $J$-integral) paths $A ; B ; \bar{C} ; D$; were used. Six paths as shown in Fig. 3 were used to study the path independence of the $J$-integral. Table 2 shows the values of SIF corresponding to these paths. It is to be noted that the accuracy in the value of $J$ decreases as the path moves near to the crack tip. Such a behaviour is not unexpected as the stress and displacement fields in the vicinity of crack-tip are not accurately represented in the present analysis which uses conventional element (without singularity). Most suitable path for accurate determination of $J$ depends upon $a / b$ ratio. Figure 4 compares the values of $K$ (via $J$ ) to the ones obtained analytically[21] for various crack length and aspect ratio. The

$$
P_{i}=A_{i} B_{i} C_{i} D_{i} ; \quad i=1,6
$$

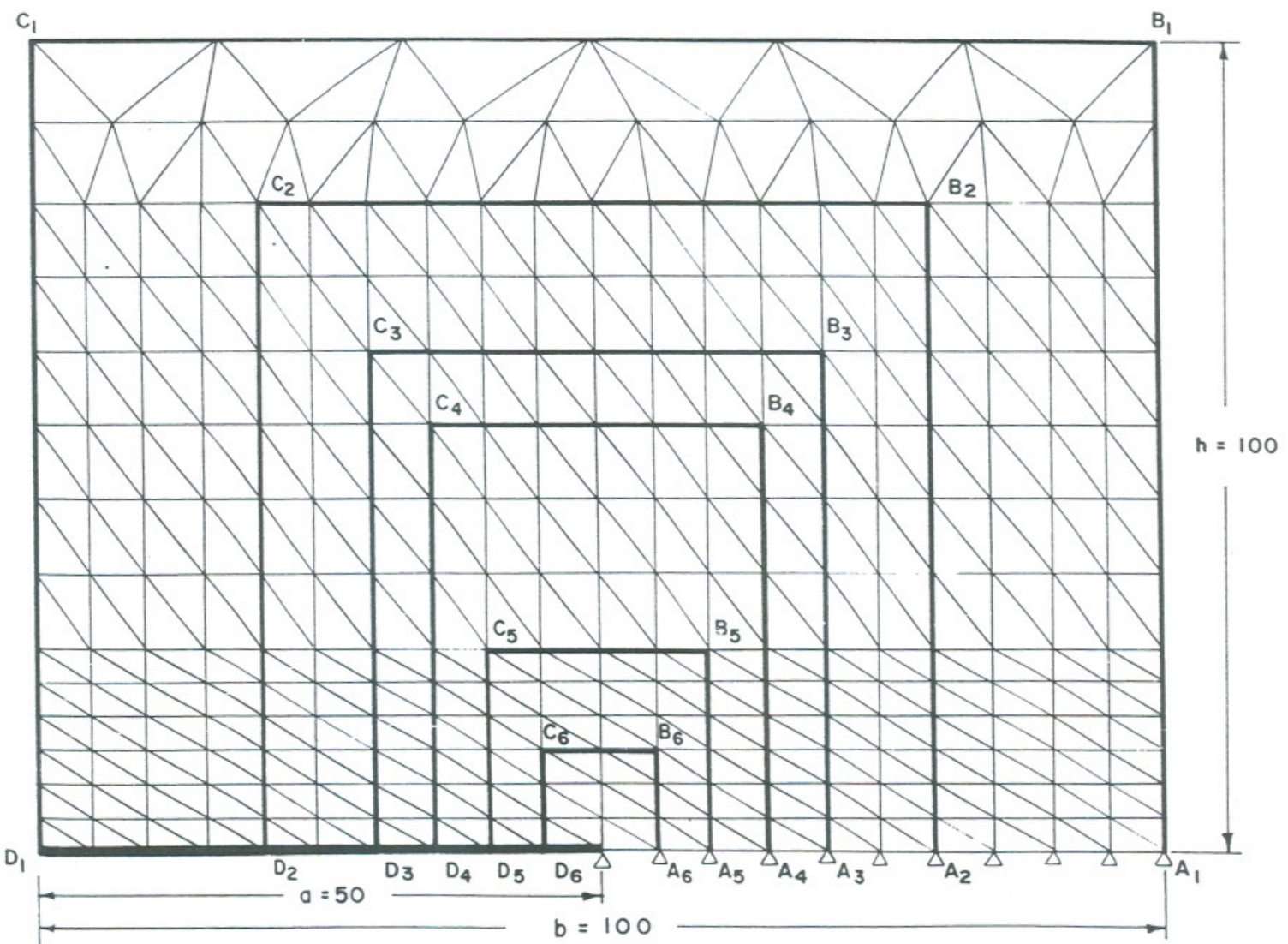

Fig. 3. Mesh 4 with various paths of contour integration. 
Table 2. Path independency of $J$-integral - edge-cracked plate without patch

\begin{tabular}{c|cc}
\hline Path & $K / \sigma \sqrt{\pi a}$ & Error (per cent) \\
\hline $\mathrm{P}_{1}$ & 2.834 & 0.56 \\
$\mathrm{P}_{2}$ & 2.796 & 1.89 \\
$\mathrm{P}_{3}$ & 2.829 & 0.73 \\
$\mathrm{P}_{4}$ & 2.853 & 0.10 \\
$\mathrm{P}_{5}$ & 2.828 & 0.77 \\
$\mathrm{P}_{6}$ & 2.713 & 4.80 \\
\hline
\end{tabular}

$h / b=1 \cdot 0 ; a / b=0 \cdot 5$.

$K_{\text {ref }} / \sigma \sqrt{\pi a}=2 \cdot 85[21]$.

good comparison establishes the efficacy of the present analysis to edge-cracked plates without patches.

Centre-cracked plates without patches

The mesh used for edge-cracked plates was used for analysis of centre-cracked plates with the proper symmetry conditions. The values of SIFs for various crack length and aspect ratios are compared with the ones obtained analytically[21] in Fig. 5. The comparison is found to be good.

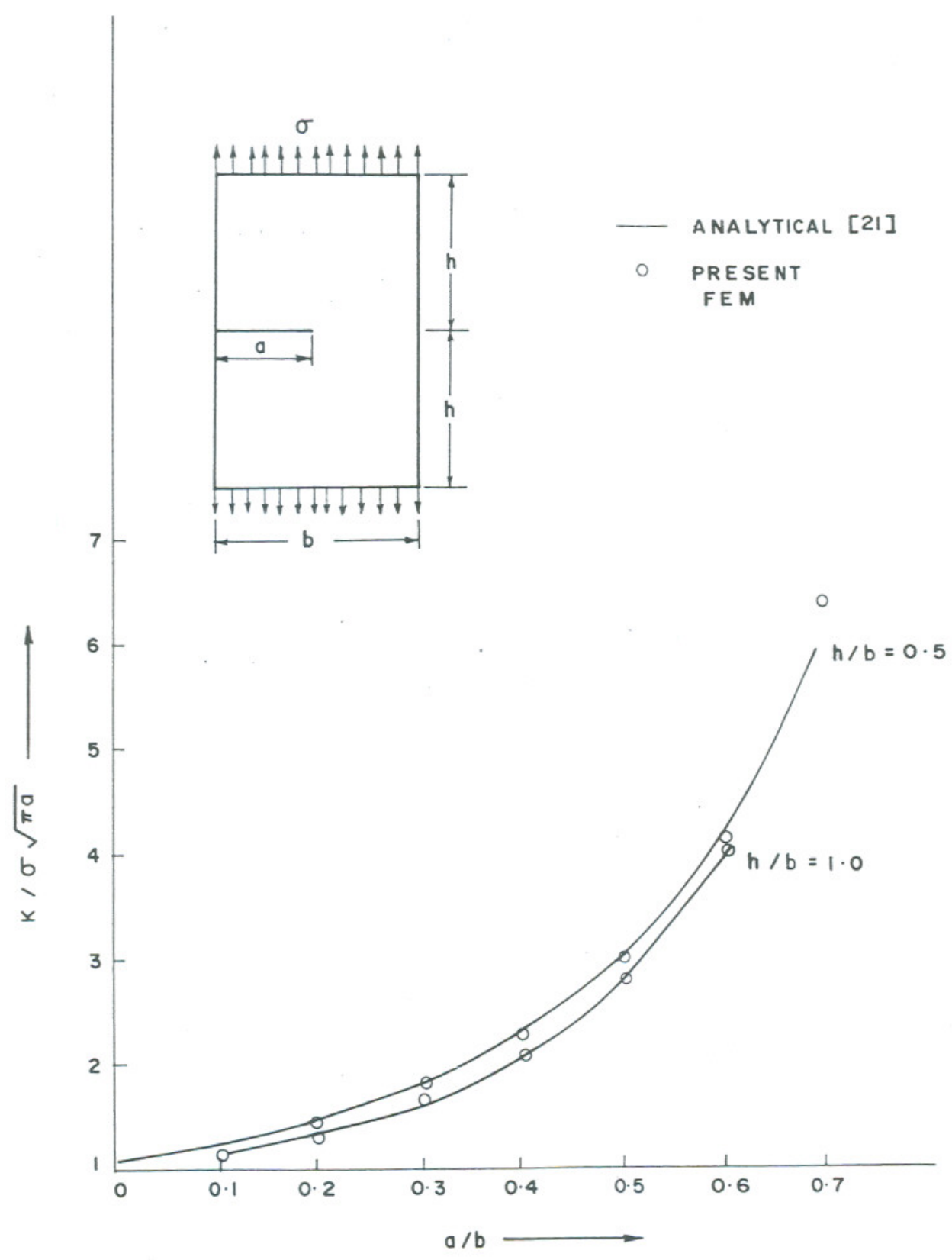

Fig. 4. Variation of SIF with crack length for edge-cracked plate. 


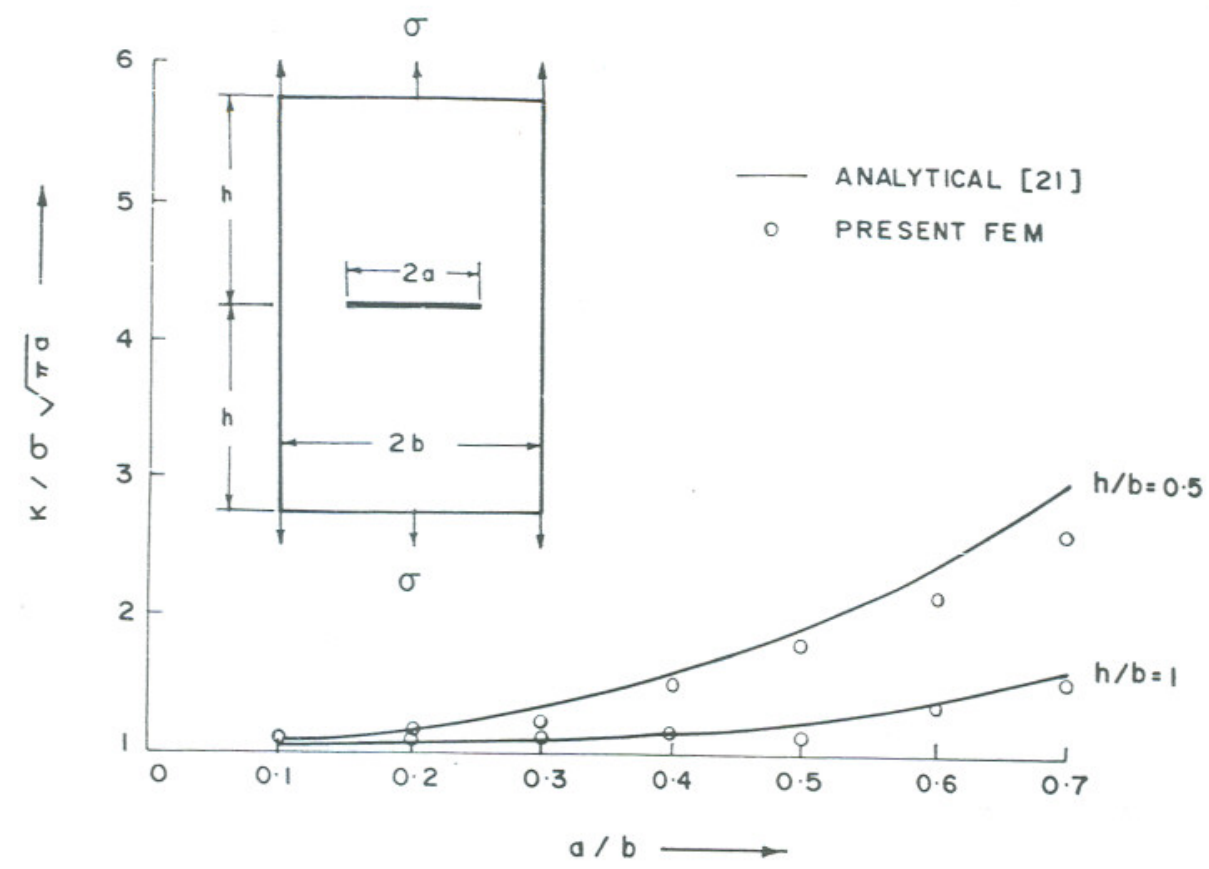

Fig. 5. Variation of SIF with crack length for centre-cracked plate.

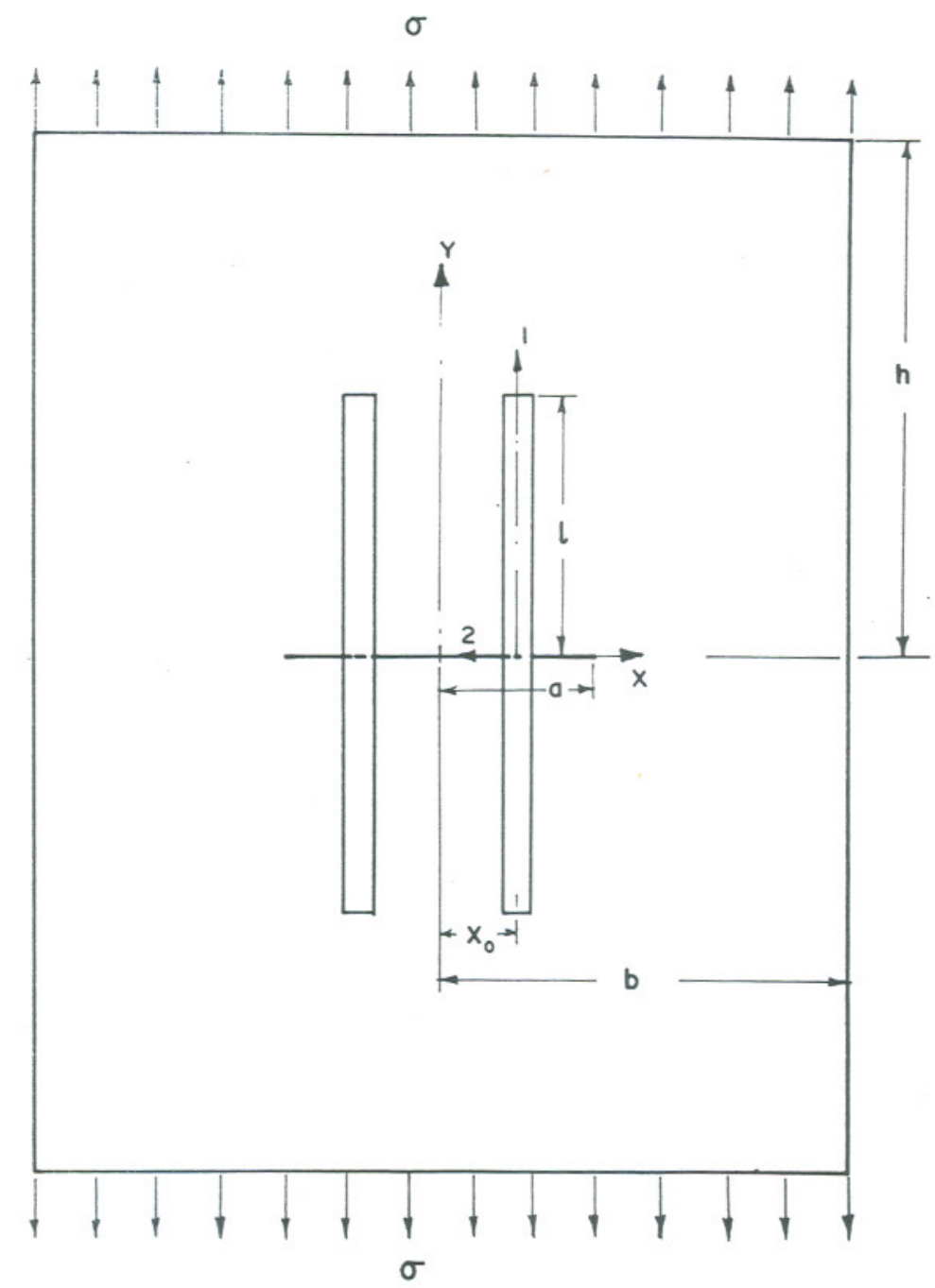

Fig. 6. Centre-cracked plate with patches. 

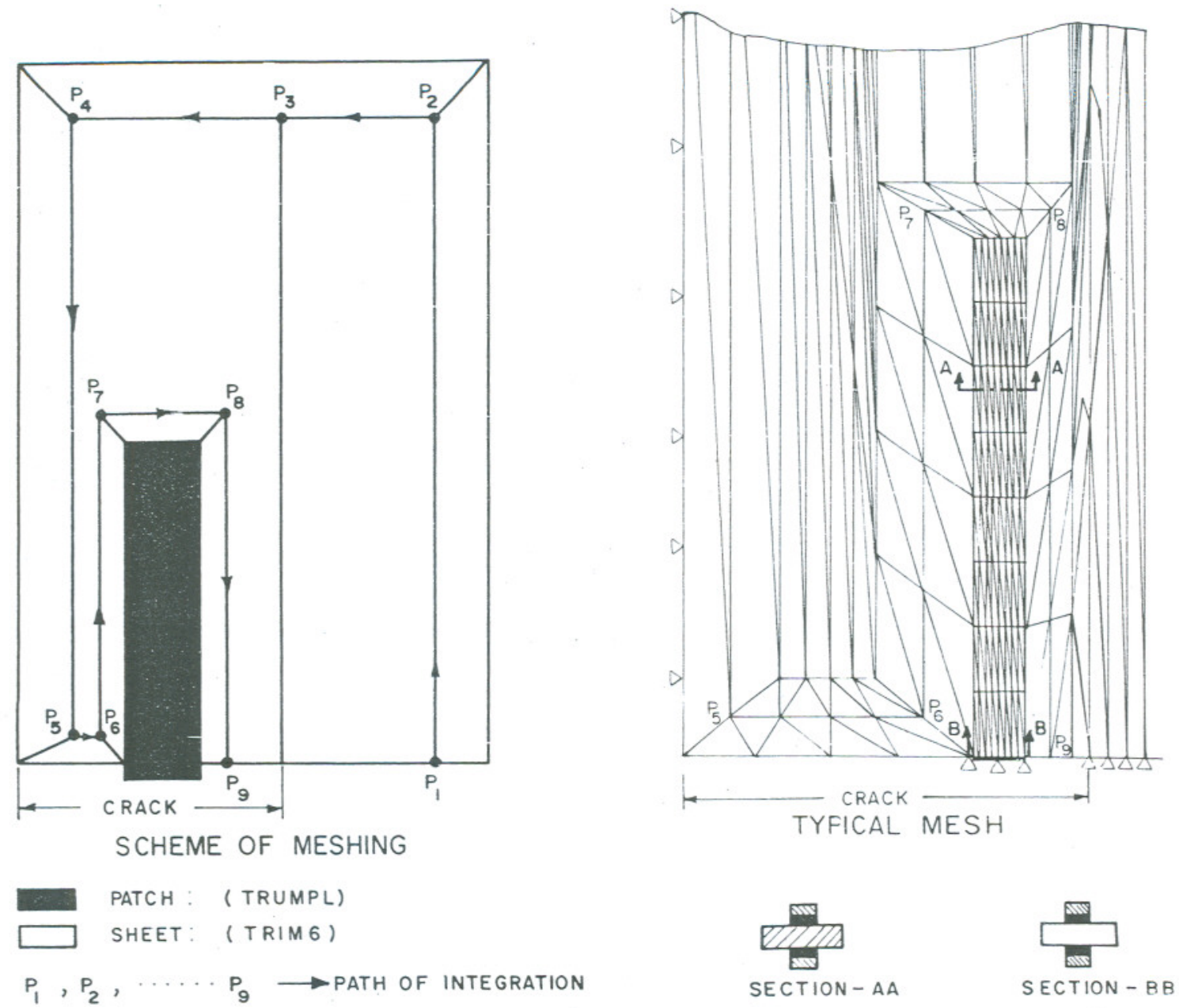

Fig. 7. Mesh for centre-cracked plate with patches-quarter plate.

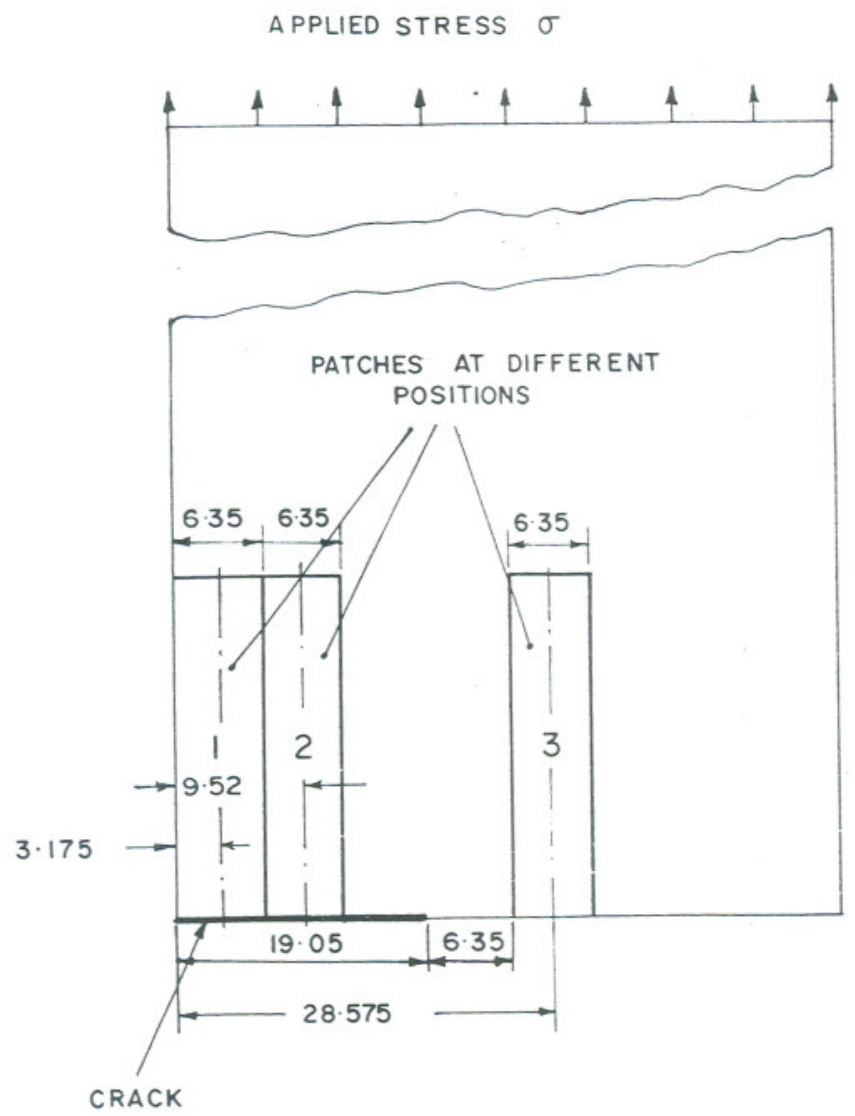

Fig. 8. Various patch positions in centre-cracked plate. 
Table 3. Comparison of SIF's obtained by present analysis, analytical techniques and photoelastic techniques

\begin{tabular}{lcc}
\hline Present analysis & Analytical & $\begin{array}{c}\text { Experimental } \\
\text { (photoelasticity) } \\
{[8]}\end{array}$ \\
\hline SIF & {$[5]$} & 13.80 \\
\hline $\left.\mathrm{N} / \mathrm{mm}^{3 / 2}\right) 14.71$ & 15.22 & 130 \\
\hline
\end{tabular}

Cracked sheet: Photoelastic material, thickness $=2.96 \mathrm{~mm}$, length $=340 \mathrm{~mm}$, width $=75 \mathrm{~mm}$, semi-crack length $=12.75 \mathrm{~mm}$, Young's modulus $=3100 \mathrm{~N} / \mathrm{mm}^{2}$, Poisson's ratio $=0.36$, shear modulus $=1140 \mathrm{~N} / \mathrm{mm}^{2}$.

Patch: Photoelastic material, thickness $=1.71 \mathrm{~mm}$, length $=40 \mathrm{~mm}$, width $=2.5 \mathrm{~mm}$, distance between two patch strip, $2 X_{0}=13.76 \mathrm{~mm}$, Young's modulus $=3100 \mathrm{~N} / \mathrm{mm}^{2}$, Poisson's ratio $=0.36$, shear modulus $=1140 \mathrm{~N} / \mathrm{mm}^{2}$.

Adhesive: Epoxy, thickness $=0.01 \mathrm{~mm}$, shear modulus $=1140 \mathrm{~N} / \mathrm{mm}^{2}$,

applied stress $=3.61 \mathrm{~N} / \mathrm{mm}^{2}(\sigma)$.

\section{Centre-cracked plates with patches}

Figure 6 shows the patched centre-cracked plates configuration which is analysed by the present technique. This configuration is selected because analytical and numerical values of SIF are available $[5,10]$. Figure 7 shows the mesh for quarter of the plate. In the patched cracked sheet region, TRUMPL element has five layers (1 of cracked sheet, 2 of adhesive and 2 of patch). In the elements in the vicinity of crack (along the crack length) cracked sheet does not exist for distances of the order of crack width. Hence in these elements, cracked sheet layer is modelled by a layer of very low modulus $\left(E=1 \mathrm{~N} / \mathrm{mm}^{2}\right)$. Results are presented in Tables 3 and 4 . It is to be noted from Table 3 that the values of SIF computed by present method compares well with the ones obtained by employing analytical and experimental techniques[5,8]. Table 4 shows the comparison of the present method with finite element method[10] for various patch positions (Fig. 8). It is to be noted that the values of SIF obtained by using the present method compare well with the ones obtained by using the finite element technique with singular element[10]. Also it is realised from Table 4 that the patches very much ahead of crack do not influence the SIF at all.

In order to study the influence of patch thickness on SIF, another configuration is examined. Table 5 describes the data used for this configuration. Figure 9 shows the influence of patch thickness on SIF for this case. Here again, good comparison with analytical method[5] is noticed.

\section{CONCLUSION}

Use of conventional finite element to compute SIF via the $J$-integral approach for cracked plates without reinforcement was already demonstrated by other investigations and is reiterated in the present investigation. Present study reveals that a conventional finite element method can be used to compute the SIF for patched cracked plates also provided one uses the $J$-integral approach.

Table 4. Comparison of SIF's obtained by present analysis and other numerical techniques

\begin{tabular}{cccc}
\hline $\begin{array}{c}\text { Patch position } \\
X_{0} \text { (Fig. 8) }\end{array}$ & Present method $K_{\mathrm{p}} / K_{\mathrm{u}}$ & Ref. [10] & \% Error \\
\hline 3.175 & 0.75 & 0.67 & 12 \\
9.525 & 0.68 & 0.60 & 13 \\
28.575 & 1.015 & - & - \\
\hline
\end{tabular}

Cracked sheet: Aluminium "'ny, thickness $=2.30 \mathrm{~mm}$, length $=635 \mathrm{~mm}$, width $=508 \mathrm{~mm}$, semicrack length $=19.05 \mathrm{~mm}$, Youi..$\quad$ nodulus $=71020 \mathrm{~N} / \mathrm{mm}^{2}$, Poisson's ratio $=0.32$.

Patch: Boron-epoxy, thickness $=0.127 \mathrm{~mm}$, length $=100.8 \mathrm{~mm}$, width $=6.35 \mathrm{~mm}$, Young's moduli: $E_{1}=208100 \mathrm{~N} / \mathrm{mm}^{2}, E_{1} / E_{2}=8.18$, Poisson's ratio $=0.168$, shear modulus $=7240 \mathrm{~N} / \mathrm{mm}^{2}$.

Adhesive: Epoxy, thickness $=0.1016 \mathrm{~mm}$, shear modulus $=965 \mathrm{~N} / \mathrm{mm}^{2}$, Poisson's ratio $=0.3$, applied stress $=0.689 \mathrm{~N} / \mathrm{mm}^{2}$. 
Table 5. Data used to study the influence of patch thickness on SIF

Cracked sheet

Aluminium alloy

Thickness $=1 \mathrm{~mm}$, length $=600 \mathrm{~mm}$, width $=200 \mathrm{~mm}$

Semi-crack length $=19.00 \mathrm{~mm}$

Young's modulus $=71,020 \mathrm{~N} / \mathrm{mm}^{2}$

Poisson's ratio $=0.32$

Patch

Carbon-epoxy

Thickness $=0.055 \mathrm{~mm}, 0.282 \mathrm{~mm}, 1.686 \mathrm{~mm}$

Length $=20 \mathrm{~mm}$, width $=2 \mathrm{~mm}$

Young's moduli: $E=208100 \mathrm{~N} / \mathrm{mm}^{2}, E_{1} / E_{2}=8.18$

Poisson's ratio $=0.168$

Shear modulus $=5000 \mathrm{~N} / \mathrm{mm}^{2}$

Adhesive

Epoxy

Thickness $=0.1016 \mathrm{~mm}$

Shear modulus $=965 \mathrm{~N} / \mathrm{mm}^{2}$

Poisson's Ratio $=0.3$

Applied stress $=0.689 \mathrm{~N} / \mathrm{mm}^{2}$

\section{REFERENCES}

[1] N. N. Damage tolerance and fatigue evaluation of structure FAA, 14 FCR Part 25, p. 571 (1977).

[2] N. N. Airplane damage tolerance requirement. MIL-Spec., 83444, USAF (1974).

[3] A. A. Baker and M. M. Hutchinson, Fibre composite reinforcement of cracked aircraft structure. Tech. Memo. ARL/ Mat. 366, (August 1976).

[4] A. A. Baker, A summary of work on application of advanced fibre composite at ARL Australia. Composite 9, 1116 (1978).

[5] Ramesh Chandra, M. V. V. Murthy, T. S. Ramamurthy and A. K. Rao, Analytical estimation of stress intensity factors in patched cracked plates. Engng Fracture Mech. 21, 479-494 (1985).

[6] A. Subramanian, Ramesh Chandra, M. V. V. Murthy and A. K. Rao, Photoelastic determination of stress intensity factors in patched cracked plates. Engng Fracture Mech. 18, 305-313 (1983).

[7] Ramesh Chandra and R. Sunder, Fatigue crack growth in patched plates under constant amplitude and flight simulation loadings. Advances in Fracture Research, Proc. Sixth Int. Conf. on Fracture, New Delhi, India, Vol. 5, pp. 3523-3532 (1984).
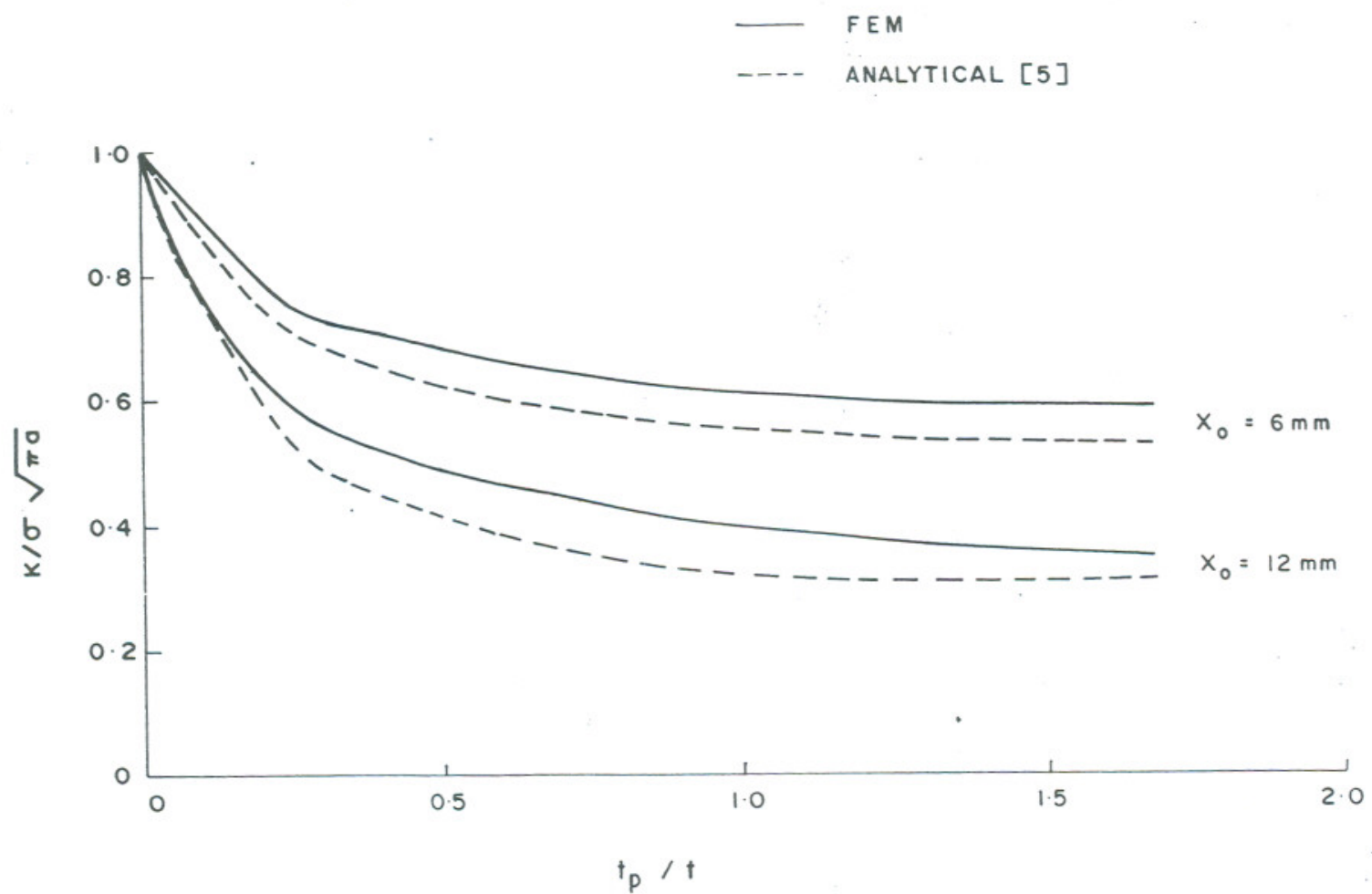

Fig. 9. Influence of patch thickness of SIF. 
[8] Ramesh Chandra, A Study on Cracked Plates with Composite Patched Reinforcements. Ph.D. Thesis. Department of Aerospace Engng, India Institute of Science (1986).

[9] R. Jones and R. J. Callinan, On the special crack tip elements in cracked elastic sheets. Int. J. Fracture 13, 51-54 (1977).

[10] R. Jones and R. J. Callinan, Finite element analysis of patched cracks. J. Struct. Mech. 7, 107-130 (1979).

[11] R. Jones and R. J. Callinan, A design study on crack patching. Fibre Sci. Technol. 14, 99-111 (1981).

[12] M. M. Ratwani, Analysis of cracked adhesively bonded laminated structures. AIAA J. 17, 988-994 (1979).

[13] A. K. Rao, I. S. Raju and A. V. Krishna Murthy, A powerful hybrid method in finite element analysis. Int. J. numer. Meth. Engng 3, 389-403 (1971).

[14] P. Tong, T. H. H. Pian and S. J. Lastry, A hybrid element approach to crack problems in plane elasticity. Int. J. numer. Meth. Engng 7, 297-308 (1973).

[15] J. R. Rice, A path independent integral and the approximate analysis of strain concentration by notches and cracks. J. appi. Mech. 35, 379-386 (1968).

[16] A. S. Kobayashi et al., A numerical and experimental in patched investigation on the use of $J$-integral. Engng Fracture Mech. 5, 291-305 (1973).

[17] D. T. Read and H. I. McHenry, Strain dependence of the J-contour integral in tensile panels. Advances in Fracture Mechanics (Edited by D. Francois et al). Pergamon Press, Oxford (1980).

[18] D. T. Read, Experimental method for direct evaluation of the $J$-contour integral. ASTM National Symposium on Fracture U.C.L.A. U.S.A. (1981).

[19] R. B. King and G. Herrmann, Application of ultrasonic stress measurements to nondestructive evaluation of the $J$ integral in elastic-plastic deformation. Engng Fracture Mech. 16, 221-227 (1982).

[20] A. Frediani, Experimental measurement of the J-integral. Engng Fracture Mech. 19, 1105-1137 (1984).

[21] D. P. Rooke and D. J. Cartwright, Compendium of Stress Intensity Factors. HMSO, London (1976).

(Received 25 September 1986) 